\title{
Ocular penetration of cyclosporin A. III: The human eye
}

\author{
David BenEzra, Genia Maftzir, Christian de Courten, Pentti Timonen
}

\begin{abstract}
The distribution of cyclosporin $A(\operatorname{CsA})$ in the blood, saliva, tears, aqueous humour, vitreous, and cerebrospinal fluid has been studied after oral treatment with $5 \mathrm{mg} / \mathrm{kg} /$ day of CsA or application of $2 \% \mathrm{CsA}$ eye drops in olive oil solution. After oral treatment all patients had high CsA levels in blood. Measurable levels of CsA were also found in the saliva and tears. Patients without any intraocular inflammation or patients with mild uveitis did not have any detectable CsA in the aqueous humour. However, patients with severe uveitis had significant levels of CsA in the aqueous humour and in the vitreous. No CsA was found in the cerebrospinal fluid of two patients with central nervous system manifestations of Behçet's disease. After local treatment with 2\% CsA eye drops no detectable levels of CsA were found in the blood, the saliva, the aqueous humour, or the vitreous even in patients with severe uveitis.
\end{abstract}

Despite intensive treatment with corticosteroids and/or cytotoxic drugs the visual outcome in chronic endogenous uveitis and more so in uveitis accompanying Behçet's disease is extremely poor. ${ }^{1}$ Because of the relentless loss of vision leading to blindness in most of these cases many forms of treatment have been tried. None, however, was satisfactory. ${ }^{1}$

With the emergence of the new immunomodulating drug cyclosporin A (Sandimmun) as an effective treatment in kidney transplantation ${ }^{2}$ its effects on experimental autoimmune uveitis (EAU) were studied. ${ }^{3}$ Owing to the benefits of CsA in the experimental animal clinical studies have been initiated. In most of them the drug was found to be effective in abating the acute intraocular inflammation and preserving vision, even in uveitides refractive to conventional therapy. ${ }^{4-7}$ However, the nephrotoxic risk of its prolonged use has inhibited its systemic use for the routine treatment of uveitis. ${ }^{89}$ To reduce the risk of toxicity of systemic treatment the possibility of using local applications has been investigated.

We report here our observations on the penetration of cyclosporin $A$ into the human eye after local ocular application or systemic ingestion of the drug.

\section{Materials and methods}

\section{PATIENTS}

Twelve patients (nine males and three females) with ocular Behçet's disease (groups 1 and 2), three patients with neuro-Behçet's disease (two males and one female, group 3 ), and six male patients undergoing routine cataract extraction without any ocular inflammation (group 4) were included in this study. In the ocular Behçet's disease groups six patients suffered from severe panuveitis at least in one eye (group 1) and six patients had signs of mild anterior uveitis with posterior involvement mainly in the peripheral fundus in one or two eyes (group 2).

In groups 1,2 , and 4 three of the six patients were either under systemic treatment with CsA or received $5 \mathrm{mg}$ CsA per $\mathrm{kg}$ at 36 hours and 12 hours before sampling was carried out. Three patients from each of these groups were given six eye drops of $2 \% \mathrm{CsA}$ in olive oil during the 36 hours preceding the sampling. The last eye drop was given one hour before the tests were carried out.

\section{COLLECTION OF SAMPLES}

All fluid samples from each patient were collected within an hour. $2 \mathrm{ml}$ of blood was withdrawn from the cubital vein into a heparinised syringe.

Excreted free saliva or saliva obtained after direct cannulation of the parotid gland was tested as previously described. ${ }^{10}$ Tears were aspirated into a $100 \mu \mathrm{l}$ pipette after introducing a grain of $\mathrm{NaCl}$ into the lower cul-de-sac.

Aqueous humour sampling was carried out after thorough washing of the ocular surface with isotonic saline solution. The procedure was explained to the patient and performed after obtaining verbal consent. Under local anaesthesia with oxybuprocaine (Novesine) eye drops $0 \cdot 2 \%, 100 \mu l$ of aqueous humour was withdrawn by tapping the anterior chamber at the upper limbus with a tuberculin syringe and a $30 \mathrm{G}$ needle.

Only four vitreous samples were studied. They were obtained from patients needing therapeutic vitrectomy. Two of the samples were obtained from patients in group 1 under systemic treatment with cyclosporin $A$. Two samples were

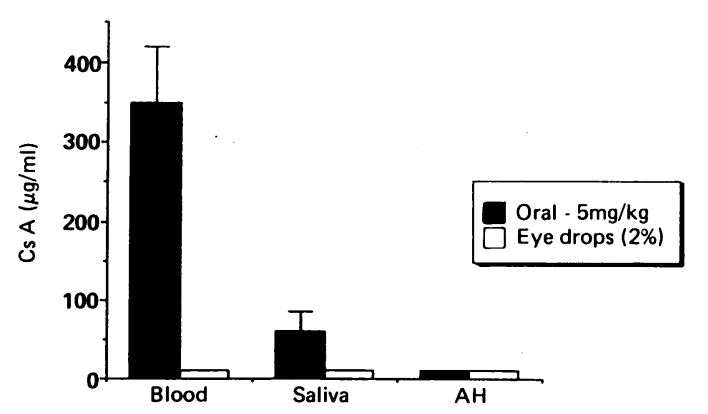

Figure 1: Levels of $C s A$ observed among patients undergoing routine cataract extraction. The drug was given either orally (5 $\mathrm{mg} / \mathrm{kg}$ ) or locally in $2 \%$ eye drops in oil solution. $A H=a q u e o u s$ humour. 
obtained from patients with severe unilateral panuveitis treated with systemic steroids. These two patients were given CsA eye drops as described earlier before vitrectomy was carried out.

Cerebrospinal fluid (CSF) was obtained from only two patients by direct puncture of the spinal space under local anaesthesia.

$25 \mu \mathrm{l}$ of the intraocular and cerebrospinal fluids were used for bacterial and viral cultures. $25 \mu \mathrm{l}$ were absorbed on a filter paper for cytology and the remaining $50 \mu \mathrm{l}$ (or more) were used for the assessment of the CsA levels.

All samples were kept at $-80^{\circ} \mathrm{C}$ until tested.

EVALUATION OF CsA LEVELS

Samples were thawed at room temperature and testing carried out with the polyclonal antibodies to CsA and its metabolites. The standard curves for detection of CsA levels were prepared according to the guidelines provided with the RIA kits of Sandoz, Basle. However, for dilution of the CsA standards (yielding known concentrations of the drugs) various fluids obtained from normal (control) animals were used and separate standard curves were prepared. The CsA level in each sample of blood, saliva, spinal fluid, tears, aqueous humour, and vitreous was estimated by reference to the appropriate standard curve for each of these fluids. New standard curves were prepared for each batch of tests. To increase further the accuracy of these standard curves fluid samples with known CsA levels obtained during the previous tests were also included in a masked manner. If more than a $15 \%$ difference in the CsA level of the repeated samples was obtained, the standard curves were repeated.

In five aqueous humour samples the levels of CsA were also estimated by high-performance liquid chromatography (HPLC).

\section{Results}

When cyclosporin A was ingested orally $(5 \mathrm{mg}$ ) $\mathrm{kg} /$ day), patients without any intraocular inflammation had a mean blood level of $350 \mu \mathrm{g} / \mathrm{l}$. Detectable levels of the drug were also observed in the saliva of these patients. However, no CsA was found in the aqueous humour in these cases (Fig 1). The aqueous humours did not show any detectable levels of CsA when the tests were repeated by HPLC. After local application of the $2 \%$ CsA eye drops in this group of patients, all fluid samples were devoid of any measurable CsA (Fig 1).

Patients with mild posterior uveitis accompanying the manifestations of ocular Behçet's

Figure 2: Levels of CsA observed among patients with mild uveitic manifestations of ocular Behcet's disease. $A H=$ aqueous humour.

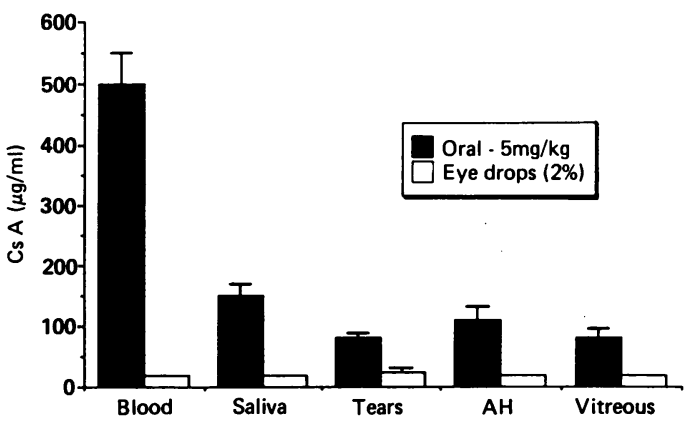

Figure 3: Levels of $C s A$ observed among patients with severe uveitic manifestations.

disease had no detectable levels of CsA in the aqueous humour after oral or local treatment (Fig 2). Low levels of CsA were detected in the tears and saliva of those patients treated systemically with $5 \mathrm{mg} / \mathrm{kg} /$ day of cyclosporin A (Fig 2).

In the group of patients with ocular Behçet's disease and severe panuveitis, 'treatment' with local eye drops did not induce any intraocular penetration of CsA. However, after systemic treatment high levels of CsA were found in the aqueous humour and in the vitreous (Fig 3). Systemic treatment resulted also in measurable levels of the drug in the saliva and tears of these patients. Measurable levels of CsA in tears were observed only in one of the patients in this group treated with eye drops (Fig 3).

The distribution of CsA in patients with Behçet's disease and central nervous system involvement was similar to that observed in the other groups after systemic treatment with the drug. In the cerebrospinal fluid, however, no measurable levels of CsA were observed (Fig 4).

\section{Discussion}

The data obtained in this study demonstrate that in the human eye topical instillation of $2 \% \mathrm{CsA}$ in olive oil does not result in any measurable levels of the drug in the aqueous humour or the vitreous even in eyes with severe panuveitis. These results correlate well with our previous observations in the rabbit (BenEzra and Maftzir, to be published) and rat eyes (BenEzra and Maftzir, to be published) using radioactive and non-ratioactive CsA in inflamed or non-inflamed eyes.

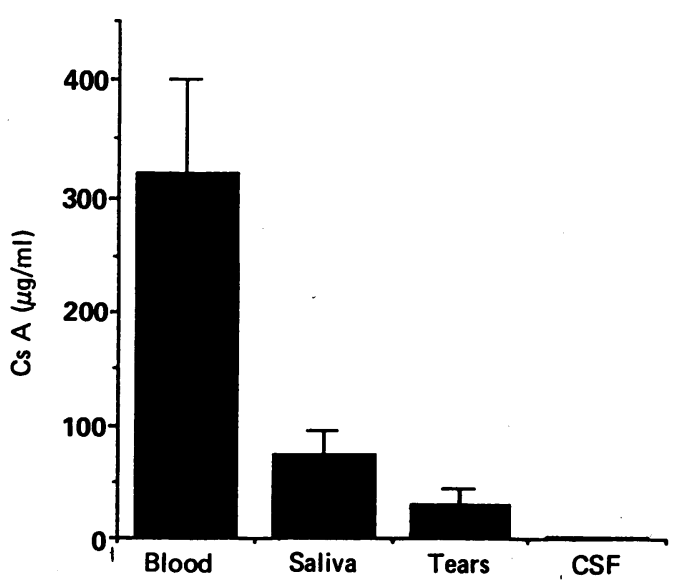

Figure 4: Levels of CsA observed among patients with CNS manifestations of neuro-Behcet's disease. 
The findings of CsA in the aqueous humour of rabbit eyes following corneal grafting as reported by others ${ }^{11}$ may be explained by the possible 'easier' penetration of the drug via the wound between the host and graft. However, the relatively high levels of CsA in the contralateral eye of these rabbits as observed by these workers are surprising. Although a 'recirculation effect' has been suggested as the explanation of similar findings, ${ }^{11} 12$ in our opinion the strong and tight blood-retinal barrier in the intact eye prevents any possible intraocular penetration via the systemic recirculation. Therefore studies demonstrating intraocular penetration of $\mathrm{CsA}$ in untreated healthy contralateral eyes after local application of oil solution (or systemic administration) of CsA should be carefully re-evaluated. Species specific differences regarding the metabolism of CsA have been observed. ${ }^{13}$ However, from our studies it appears that the ocular distribution of the drug in the rabbit, the rat, and the human eye is similar.

After oral ingestion of the drug high blood levels have been found in all patients. Significant detectable levels of CsA were also observed in saliva and tears. These results may reflect the high differential uptake of CsA in these glands. Indeed, a high specific uptake of CsA in the salivary glands of experimental animals has been demonstrated..$^{14}$ Our study further shows that specific concentration of CsA is probably also taking place in the human lacrimal gland. These findings may be helpful when considering the possible use of CsA in non-infectious inflammatory diseases affecting the salivary and/or lacrimal glands.

Regarding the intraocular penetration of CsA, however, there is a definite and clear differentiation between the findings observed in the noninflamed or mildly inflamed eyes on the one hand, and the eyes with severe uveitis on the other. Obviously, in the latter, the breakdown of the blood-retinal barrier and the leaky nature of the intraocular blood vessels allow penetration of the lipophilic molecule of CsA into the aqueous humour and vitreous. These results are in line with the observations of measurable levels of $\mathrm{CsA}$ in the aqueous humour of a few patients with uveitis ${ }^{15}$ and Behçet's disease. ${ }^{16}$

In earlier studies we have observed detectable levels of CsA in the aqueous humour after local application of the drug in rabbit eyes with severe intraocular inflammation (BenEzra and Maftzir, to be published). High levels of CsA in the aqueous humour have also been observed in the rat eye when extensive damage of the cornea was induced by topical application of absolute alcohol eye drops (BenEzra and Maftzir, to be published). In the human eye, however, as shown in this study, no detectable levels of CsA were found either in the aqueous humour or in the vitreous after local application of $2 \% \mathrm{CsA}$ in olive oil even in eyes with severe panuveitis. These differences between the inflamed rabbit eye and the human eye with uveitis may be due to the fact that the corneas of the inflamed rabbit eyes were oedematous, while in the patients' eyes with uveitis the corneas were not affected.

Our findings clearly demonstrate that detectable levels of cyclosporin $A$ in the human eye are observed only in eyes with severe uveitis after systemic ingestion of the drug. Thus breakdown of the blood-retinal barrier is necessary to allow intraocular penetration of CsA. After topical application of $2 \% \mathrm{CsA}$ oil solution the drug is not observed within the human eye, even in eyes with severe panuveitis.

1 BenEzra D, Cohen E. Treatment and visual prognosis in Behcet's disease. BrF Ophthalmol 1986; 70: 589-92.

2 Calne RY, White DJ. The use of cyclosporin A in clinical organ grafting. Ann Surg 1982; 9: 330-7.

3 Nussenblatt RB, Salinas-Carmona MC, Gery I, Cevario S, Wacker WB. Modulation of experimental autoimmune uveitis with cyclosporin A. Arch Ophthalmol 1982; 110: uveitis $1146-9$.

4 Nussenblatt RB, Palestine AG, Chan CC. Cyclosporin A therapy in the treatment of intraocular inflammatory disease resistant to systemic corticosteroids and cytotoxic agents. Am f Ophthalmol 1983; 96: 275-82.

5 Graham EM, Sanders MD, James DG, Hamblin A Grochowska EK, Dumonde D. Cyclosporin A in the treatment of posterior uveitis. Trans Ophthalmol Soc UK 1985; 104: 146-51.

6 BenEzra D, Cohen E, Chajek T, Friedman G, Pizanti S, Matamoros N. Evaluation of conventional therapy versus cyclosporin A in Behcet's disease. Doc Ophthalmol Proc Ser 1987; 50: $269-75$.

7 BenEzra D, Cohen E, Rakatomalala M, et al. Effect of cyclosporin A in endogenous uveitis. Transplant Proc 1988; 20 (suppl 4): 122-7.

8 Svenson K, Bohman SO, Hallgren R. Renal interstitial fibrosis and vascular changes. Occurrence in patients with autoimmune diseases treated with cyclosporine. Arch Intern Med 1986; 146: 2007-10.

9 Palestine AG, Austin HA, Balow JE, et al. Renal histopathologic alterations in patients treated with cyclosporine for uveitis. N Engl F Med 1986; 314: 1293-98.

10 Pizanti S, Maftzir G, BenEzra D. Oral health parameters in Behçet's disease - a comparison between conventional therapy and cyclosporin A treatment. In: Lehner T, Barnes $\mathrm{G}$, eds. Recent advances in Behcet's disease. London: Royal G, eds. Recent advances in Behçet's disease.

11 Bell TAG, Hunnisett AG. Cyclosporin A: tissue levels following topical and systemic administration to rabbits. $\mathrm{Br}$ f Ophthalmol 1986; 70: 852-5.

12 Wiederholt $M$, Kossendrup D, Schulz W, Hoffman F. Pharmacokinetics of topical cyclosporin $A$ in the rabbit eye. Invest Ophthalmol Vis Sci 1986; 27: 519-24.

13 Venkataramanan $R$, Wang CP, Habucky $\mathrm{K}$, et al. Speciesspecific cyclosporine metabolism. Transplant Proc 1988; 20 (suppl 2): 680-3.

14 Backman L, Brandt I, Dallner G, Ringden O. Tissue distribution of $\mathrm{H}^{3}$ cyclosporine A in mice. Transplant Proc 1988; 20 tion of $\mathrm{H}^{3}$ cyclosporin

15 Palestine AG, Nussenblatt RB, Chan CC. Cyclosporine penetration into the anterior chamber and cerebrospinal fluid. Am f Ophthalmol 1985; 99: 210-1.

16 Tabbara KF, Gee SS, Alvarez H. Ocular bioavailability of cyclosporine after oral administration. Transplant Proc 1988 ; 20 (suppl 2): 656-9. 